\title{
Facilitation of both "same" and "different" judgments of letter strings by familiarity of letter sequence
}

\author{
ARNOLD D. WELL, ALEXANDER POLLATSEK, and ROBERT M. SCHINDLER \\ University of Massachusetts, Amherst, Massachusetts 01002
}

\begin{abstract}
Three experiments employing simultaneous matching were performed to extend recent findings that three kinds of familiarity-familiarity of letter sequences, familiarity of display configuration, and familiarity of letter orientation-facilitate the matching of letter strings for "same" responses and sometimes for "different" responses. It was found that letter sequence familiarity facilitated "same" responses even when the letter strings were in an unfamiliar orientation or configuration and also facilitated "different" responses whenever the task required that a substantial portion of the display be processed before a response could be initiated. A three-stage model of the simultaneous letter-string matching task was developed. This model, which assumes that the same processes account for both "same" and "different" responses, was consistent with findings obtained when there were small differences between string pairs. Discrepant findings obtained when there were large differences between string pairs may have been produced by the premature initiation of responses.
\end{abstract}

A continuing issue in experimental psychology has been whether previous experience with a stimulus changes the way in which it is perceived. Recently, a considerable body of work has addressed this problem using as stimulus material collections or arrays of letters which form "familiar" sequences (usually words, or at least meaningful or pronounceable nonwords, e.g., FBI and BIF) and "unfamiliar" sequences (usually unpronounceable nonwords). While it has been known for a very long time (Cattell, 1886) that much more can be recalled from a briefly presented display made up of words than from one made up of unrelated letters, recent approaches have been directed at demonstrating that the effect is indeed on "perception" rather than on postperceptual processes. Clearly, Cattell's results could have been due to subjects' being able to better remember or guess at tachistoscopically presented words rather than seeing them any faster or more efficiently.

Several techniques seem now to be in general use for studying this familiarity effect (FE) (e.g., Eichelman, 1970; Krueger, 1970; Reicher, 1969). We will, however, confine our discussion in this paper to only one of these techniques, the simultaneous matching task. In this task, subjects are presented with a display consisting of two strings of letters and are required to indicate whether or not the two strings are the same. Usually, the strings are displayed until a response is made. The advantages of employing this task are clear. A forced-choice "same" or "different"

This research was supported in part by National Science Foundation Social Science Development Grant GU-4041, and in part from the Research Council of the University of Massachusetts to the first author. Requests for reprints should be sent to Arnold D. Well, Department of Psychology, University of Massachusetts, Amherst, Massachusetts 01002. response may be obtained, limiting the usefulness of guessing. Moreover, if the letter strings remain displayed until a response is made, direct effects of memory on the response are minimized. Unfortunately, one major problem with this technique is equally clear. In order for a response to be made, information from the display must be extracted and compared. It is possible that much or all of the advantage of familiar over unfamiliar stimuli obtained with this task reflects the ease of comparing information extracted from the display rather than the ease of extracting or encoding it. As Egeth and Blecker (1971) have pointed out, results obtained using this technique should be generalized only with considerable caution.

In any event, if this technique is to be further used to study the effects of familiarity (however defined) on perception, it is desirable to know more about the conditions under which FEs are obtained.

Certain experiments in the literature have implied that advantages of familiar sequences of letters over unfamiliar ones hold only under restricted conditions (Hochberg, 1968) and then only for "same" judgments (Barron \& Pittenger, 1974; Egeth \& Blecker, 1971). The experiments reported here represent an attempt to demonstrate the robustness and generality of the effects of familiarity in the simultaneous matching task whenever a substantial portion of the stimulus array must be dealt with before a response is initiated.

While the familiarity of the order of letters in a string can be varied (e.g., WORD vs. RWDO), the particular fashion in which the array is displayed may also be more or less familiar. The letter sequence $W$, $\mathrm{O}, \mathrm{R}, \mathrm{D}$ is more commonly encountered when displayed as a row than as a column with $\mathrm{W}$ at the top 
and $D$ at the bottom. In both cases, the order of letters is the same. but the shapes and, hence, at least some of the visual features of the two displays are quite different. We will distinguish between these two types of familiarity by referring to the former as familiarity of letter sequences and the latter as familiarity of configuration. The question can be posed as to whether the familiarity of letter sequences, even in the absence of a highly familiar configuration, is sufficient to produce a FE.

There is evidence that it is not. While Eichelman (1970) found large advantages in matching times for word pairs over nonword pairs when displaying either pairs of words or pairs of nonwords in horizontal rows (one above the other). Hochberg (1968) found no differences between judgments of pairs of words and pairs of nonwords displayed in columns. Hochberg. however, employed as a dependent variable the number of 1.35-sec "looks" required to make a "same" or "different" judgment. As Egeth and Blecker (1971) have pointed out, this may not have permitted a sensitive enough measure of small differences in judgment time.

To rule out the possibility that something peculiar to vertical as opposed to horizontal configuration caused Hochberg's results, Egeth and Blecker (1971, Experiment 5) compared matching times for pairs of CVC trigrams displayed as vertical columns (a) when the displays were upright and (b) when the displays were rotated $180 \mathrm{deg}$.

They found that upright displays were matched more rapidly than rotated ones (at least for "same" responses). This result is certainly consistent with their finding (Experiment 1) that upright pairs of letters can be matched more rapidly than rotated pairs of letters. It does not, however, address the issue of whether familiar letter sequences can be matched more rapidly than unfamiliar sequences for vertical displays. since no analyses concerning the effects of sequence familiarity were reported for either the upright or the rotated conditions.

In Experiment $I$ of the present paper, the familiarity of letter sequences was varied when letter strings were presented in columns. In Experiments II and III, the effects of manipulating letter sequence familiarity were compared for displays of upright horizontal strings (row's) and the same strings rotated $180 \mathrm{deg}$.

One other issue of interest has to do with the finding that familiarity facilitates "same" responses but not "different" responses (Barron \& Pittenger. 1974; Egeth \& Blecker, 1971). This result is inportant because it implies that "same" and "different" responses are produced by separate processes (the former influenced by familiarity and the latter not). It also implies that "different" responses are not the result of a second stage of processing following a fast "global" check for identity. since, then, familiarity would have to affect this first stage and hence both "same" and "different" response times.

Eichelman (1970), however, found FEs for both "same" and "different" responses, although the effects were larger for "same" responses. Henderson (1974) also found effects for both "same" and "different" responses using as familiar letter strings orthographically illegal acronyms (e.g., USSR). Barron and Pittenger (1974) and Henderson (1974) have commented on procedural differences between these experiments. They noted that both Eichelman and Henderson blocked the familiarity variable and informed subjects as to which type of material they would be seeing on each block of trials. while Egeth and Blecker (1971) did not. This difference in procedure suggests the possibility that subjects may have been able to switch the nature of their processing so as to be able to take advantage of familiarity only in blocked conditions. This idea was investigated by Barron and Pittenger (1974), who assessed the effects of practice and blocked vs. mixed presentation on the matching of familiar and unfamiliar strings. They found a small FE for "different" jud gments only early in practice and then only when blocked presentation was employed. They suggest that subjects in the blocked condition first adopted a strategy which employed semantic and orthographic information and then, with more practice, shifted to one in which graphemic features alone were used.

The discrepancy in findings with respect to FEs for "different" responses may be resolvable in view of evidence that the processes responsible for "different" responses are self-terminating (Bamber, 1969; Eicheiman, 1970). Were these self-terminating processes actually intluenced by familiarity, it would still be difficult to observe the effects of familiarity in some situations, precisely because they were self-terminating.

Looked at in this way, it is not surprising that Egeth and Blecker (1971. Experiment 4) found no large effects of familiarity on "different" responses to pairs of CVC trigrams. If not all letters are fully processed by the "different" processor before a response is initiated, then what is processed may not be more familiar for meaningful CVC trigrams than for nonmeaningful CVC trigrams. Eichelman and Henderson may have obtained FEs for "different" responses, not so much because they employed blocking. but because both experiments required lairly extensive processing of strings before "different" responses could be initiated. Eichelman's "different" word and nonsense string pairs often did not differ from one another by more than one or two positions. Henderson's strings usually differed in all positions but were presented side by side (e.g., USSR VPMC) so at least all of the leftmost strings would likely have 
been processed before "different" responses could be generated.

While Barron and Pittenger varied the number of letters by which string pairs differed, over $90 \%$ of their "different" pairs differed in at least three of five possible positions. In particular, 34 of 36 "different" pairs differed in at least one of the first (leftmost) two positions. Barron and Pittenger commented that subjects found pairs of strings differing in as few as two positions to be particularly difficult and, in this case, nonwords were matched approximately 120 msec more slowly than words. When differences were more salient, the "different" processor may have fully processed only small segments of strings. The effects of familiarity may not have been potent for these small segments.

This suggests that to assess the effects of familiarity on "different" responses, the familiarity of what the "different" processor actually processes must be considered. Presumably, the amount of the stimulus array that is processed can be manipulated by varying the salience of differences when they occur. In the present study, this was pursued by using, in Experiments I and II, the same stimuli used by Eichelman and by using, in Experiment III, a set of stimuli in which differences were even less salient-letter strings never differing in more than one position.

\section{EXPERIMENT I}

Experiment I was essentially a replication of Eichelman's (1970) Experiment 1, with two major modifications: (a) familiarity was not blocked-on a given trial, the subject never knew whether he was to be presented with a word pair or a nonword pair, and (b) letter strings were presented in columns rather than in rows (see Figure 1a).

\section{Method}

Subjects. Twelve University of Massachusetts undergraduates served as subjects and received course cred it for their participation. The data from two additional subjects were discarded because their error rates exceeded the predetermined cutoff level of 5\%. Each subject participated for two 1 -h sessions on successive days.

Apparatus and Stimuli. A Hewlett-Packard $2114 \mathrm{~B}$ computer was used to display columns of capital letters on an HP-1300A X-Y display oscilloscope. Each letter was constructed by illuminating the appropriate pattern of points in a matrix 13 points high by 9 points wide. The computer also recorded responses and measured the response time (RT). The subjects were run individually, and set approximately $5 \mathrm{ft}$ from the oscilloscope screen in a dimly lit sound-damped room.

The stimulus display for a single trial consisted of two vertical columns of letters presented side by side. The lateral separation between columns varied randomly from block to block and could assu me one of four values $(2,12,20$, or $47 \mathrm{~min})$. This manipulation was made to test the possibility that when columns were presented very close to one another, the subject might have been more likely to organize their contents as a single column of letter pairs and hence been less likely to capitalize on the familiarity of letter sequences. For half of the blocks of trials, four-letter columns were displayed.
$\begin{array}{cc}T & T \\ H & H \\ R & R \\ U & U \\ S & S \\ H & H\end{array}$

(a)
THRUSH

THRUSH

(b)

(c)
Figure 1. Examples of configurations of displays used (a) in Experiment $I$ and (b) and (c) in Experiments $I$ and III.

and for the remainder of the blocks, six-letter columns were displayed. Each letter was . 39 in. high and could be as much as $.34 \mathrm{in}$. wide. The vertical visual angles subtended by the four- and six-letter columns were 1.7 and $2.6 \mathrm{deg}$, respectively.

Each trial block consisted of 36 trials. One-fourth of the displays in a block were identical words, one-fourth were differing words. one-fourth were identical nonwords, and one-fourth were differing nonwords. The actual word and nonword strings used were those generated by Eichelman (1970). Four-letter pairs that differed could (with equal frequency) differ in one, two, or all four positions. Six-letter strings could differ in two, four, or all six positions. Words and nonwords were equated for overall letter frequency by using a pool of all of the letters in the words to form the nonwords.

Procedure. Six subjects matched four-letter string pairs on the first day and six-letter string pairs on the second. This order was reversed for the other six subjects. Each day began with 72 practice trials, followed by four blocks of trials from which data were recorded.

The subjects were instructed to pay close attention to the screen, to keep their hands lightly over the two response keys, and to response "same" (with their left hands) or "different" (with their right hands) as quickly and as accurately as possible. A trial began with the appearance of a plus sign in the center of the display for $.5 \mathrm{sec}$ as a fixation point. One second after the onset of the plus, the stimulus pair was displayed. Following a response, the computer extinguished the display, recorded the response latency, and presented the feedback words "correct" or "error" for $1 \mathrm{sec}$. The intertrial interval was $3.5 \mathrm{sec}$.

\section{Results and Discussion}

When an analysis of variance including both "same" and "different" RTs was performed, it was found that there was a highly significant main effect of response type $[F(1,11)=34.7, p<.01]$ and also that the effect of letter sequence familiarity was significantly larger for "same" than for "different" responses $[F(1,11)=9.5, \mathrm{p}<.025]$. Consequently, "same" and "different" RT data were analyzed separately, using four-way analyses of variance: Familiarity by Length of String by Lateral Separation by Subjects. The mean RTs for "same" and "different" responses expressed as a function of familiarity, and string length are presented in Table 1. The major finding was that for "same" responses word matches were performed an average of $91 \mathrm{msec}$ faster than nonword matches $[F(1,11)=$ $27.1, \mathrm{p}<.001]$. In addition, "same" RTs were faster for four-letter strings than for six-letter strings $[F(1,11)=6.60, p<.05]$ and increased significantly with lateral separation of the columns $[\mathrm{F}(3,33)=$ $5.67, p<.005]$. Significant FEs were obtained for each lateral separation employed, and while there was 
Table 1

Mean Response Times for Experiment I* (in Milliseconds)

\begin{tabular}{|c|c|c|c|c|}
\hline \multirow[b]{2}{*}{$\begin{array}{l}\text { Type of } \\
\text { Response }\end{array}$} & \multicolumn{2}{|c|}{$\begin{array}{c}\text { Length and Type } \\
\text { Four-Letter } \\
\text { Strings }\end{array}$} & \multicolumn{2}{|c|}{$\begin{array}{l}\text { String Presented } \\
\text { Six-Letter } \\
\text { Strings }\end{array}$} \\
\hline & Words & $\begin{array}{l}\text { Non- } \\
\text { words }\end{array}$ & Words & $\begin{array}{l}\text { Non- } \\
\text { words }\end{array}$ \\
\hline "Same" $"$ "Different" & $\begin{array}{r}1061 \\
868\end{array}$ & $\begin{array}{r}1132 \\
910\end{array}$ & $\begin{array}{r}1186 \\
864 \\
\end{array}$ & $\begin{array}{r}1276 \\
863 \\
\end{array}$ \\
\hline
\end{tabular}

${ }^{*}$ Averaged over lateral separation conditions.

some tendency for FEs to increase with lateral separation, this effect was not significant. While the analysis of variance of "different" responses revealed no significant effects, there was a small $(20 \mathrm{msec})$ overall tendency for word pairs to be matched more rapidly than nonword pairs. This tendency was strongest when differences were least salient (e.g., $37 \mathrm{msec}$ when string pairs differed in only one position) and was totally absent when string pairs differed in all positions. While the overall error rate was only $3.2 \%$, errors exceeded $20 \%$ in conditions in which string pairs differed in only one position. This finding suggests that subjects often did not process the strings completely before initiating "same" responses.

From the $1 / 12$ th of the data in which string pairs differed in only one position, it was possible to look at RT as a function of serial position of difference. RTs increased monotonically with increasing serial position of difference, suggesting (not surprisingly) that subjects were primarily employing a top-tobottom order of processing. The highest error rates (approximately $28 \%$ for both word and nonword pairs) occurred when strings differed only in the last (bottom) position. In this condition, word pairs had a 110 -msec advantage in matching time, suggesting that when subjects did process the string pairs fairly completely, there was a tendency for familiarity to facilitate the response. Even this large difference was not significant. however, given the small amount and highly variable nature of the data collected for this condition.

The results of this experiment demonstrate that, even when the familiarity variable is not blocked and letter sequences are presented in relatively unfamiliar configurations. FEs may be obtained for "same" responses. The results are somewhat ambiguous as to whether FEs can be obtained for "different" responses, although they suggest that when subjects must process much of the display before initiating a "different" response, a FE is more likely to occur than when differences occur in the first few positions processed.

\section{EXPERIMENT II}

Although Experiment I demonstrated that reliable FEs could be obtained for the word and nonword pairs used by Eichelman (1970) even when string pairs were presented in columns, the effects obtained were not as large as those reported by Eichelman. ${ }^{1}$ It is difficult to make much of this difference, as the studies differed in ways other than display configuration (most particularly, blocking of the familiarity variable and amount of practice given subjects). It seems plausible, however, that the effects of letter-string familiarity should be smaller for vertical dis plays than for horizontal ones. Subjects in Experiment I may have had difticulty in scanning this display in a top-to-bottom fashion and been willing to terminate processing of vertical displays prematurely. Experiment II employed essentially the same procedure as Experiment $I$ to determine the size of the FEs when strings were presented in rows. In Experiment II, for half of the trial blocks, the same letter sequences that were used in Experiment I were again matched when displayed in upright rows (see Figure $1 \mathrm{~b}$ ). For the remaining trial blocks, the entire displays were rotated $180 \mathrm{deg}$ (see Figure 1c).

This latter manipulation was thought to be useful for two reasons. So far in this paper, three kinds of familiarity have been mentioned, letter sequence familiarity (e.g., words vs. nonwords), configuration familiarity (e.g., rows vs. column displays), and orientation familiarity (e.g., upright strings vs. rotated strings). There seems to be no reason to expect all of these kinds of familiarity to influence processing in exactly the same way. Orthogonally varying two kinds of familiarity within the same experiment allows some investigation of this possibility. If, for instance, in Experiment II, familiarity of letter sequence and familiarity of letter orientation operated primarily on separate stages of processing, little or no interaction might be expected between their effects. Also, Egeth and Blecker (1971) reported an absence of the effects of familiarity on "different" response times, not only when the familiarity manipulation was one of trigram meaningfulness (Experiment 4 ), but also when it was one of display orientation (upright vs. rotated displays of trigrams-Experiment 5). Given that there is clearly an effect of rotation on "same" judgments to pairs of letters (Egeth \& Blecker, Experiment 1), it seems implausible that there should not be an effect of rotation on "different" responses to pairs of letter strings, as, for these displays, subjects must search through identical letter pairs until a difference is encountered. In Experiment II, the effects of both familiarity manipulations on both "same" and "different" responses could be assessed. 


\section{Method}

Subjects. Twenty-four University of Massachusetts undergraduates served as subjects and received course credit for their participation. Each subject participated for two 1-h sessions separated by 2 days.

Apparatus and Stimuli. The same apparatus and stimulus set as in Experiment I were used. Letter strings were, however, displayed in either upright or rotated rows (see Figure 1). During the experiment, strings varied as to string type (word or nonword), length (four or six letters), and orientation upright or rotated) but for a given block of 36 trials were all the same length and orientation. Four-letter strings subtended a horizontal visual angle of $1.6 \mathrm{deg}$, while six-letter strings subtended a horizontal visual angle of $2.3 \mathrm{deg}$. Strings were separated by about one letter wid th, and hence the total vertical visual angle subtended was about $1.4 \mathrm{deg}$.

Procedure. The subjects were run individually, as in Experiment I. At the beginning of each session, the subject received three 24-trial practice blocks, one of which contained rotated displays. Data were collected from four 36-trial blocks on each day with four- and six-letter blocks presented in aabb order on the first day and in bbaa order on the second. The upright and rotated trial blocks were presented in abba order the first day and in baab order the second.

\section{Results and Discussion}

The mean RTs for "same" and "different" responses expressed as a function of string type (word or nonword), length, and orientation are presented in Table 2. When an analysis of variance including both "same" and "different" RTs was performed, it was found that there was a highly significant main effect of response type $[F(1,23)=23.2, p<.001]$, and also that the effect of letter sequence familiarity was significantly larger for "same" than for "different" responses $[F(1,23)=83.6, p<.001]$. Consequently, "same" and "different" RT data were analyzed separately using four-way analyses of variance: Length by Orientation by String Type by Subjects. For "same" responses, word pairs were matched more rapidly than nonword pairs $[F(1,23)=113.6$, $\mathrm{p}<.001]$. While rotated displays were matched more slowly than upright displays $[\mathrm{F}(1,23)=74.5$, $p<.001]$, there was no evidence of any interaction between string type and orientation $(F<1)$. The advantage of word pairs over nonword pairs was almost identical for upright $(181 \mathrm{msec})$ and rotated (182 msec) strings. The effects of letter-sequence familiarity on matching time for upright strings conform closely in magnitude to those reported by Eichelman (1970) for "same" responses, suggesting that the manipulation of blocking the letter sequence familiarity variable may not be a potent one. In addition, six-letter strings were responded to more slowly than four-letter strings $[F(1,23)=11.4$, $\mathrm{p}<.005]$.

For "different" responses, word pairs were matched more rapidly than nonword pairs $[F(1,23)=$ 12.4, $\mathrm{p}<.005$ ]. In contrast to the results of Egeth and Blecker's Experiment 5 for "different" responses, rotated strings were responded to more
Table 2

Mean Response Times for Experiment II (in Milliseconds)

\begin{tabular}{|c|c|c|c|c|}
\hline \multirow{2}{*}{$\begin{array}{l}\text { Orien- } \\
\text { tation }\end{array}$} & \multicolumn{2}{|c|}{$\begin{array}{l}\text { Length and Type } \\
\text { Four-Letter Strings }\end{array}$} & \multicolumn{2}{|c|}{$\begin{array}{l}\text { String Presented } \\
\text { Six-Letter Strings }\end{array}$} \\
\hline & Words & Nonwords & Words & Nonwords \\
\hline & \multicolumn{4}{|c|}{ "Same" Responses } \\
\hline Upright & 728 & 898 & 792 & 984 \\
\hline \multirow[t]{2}{*}{ Rotated } & 973 & 1182 & 1134 & 1291 \\
\hline & \multicolumn{4}{|c|}{ "Different" Responses } \\
\hline Upright & 795 & 861 & 747 & 822 \\
\hline Rotated & 932 & 970 & 912 & 906 \\
\hline
\end{tabular}

slowly than upright ones $[F(1,23)=49.5, \mathrm{p}<.001]$. In addition, six-letter strings were responded to more slowly than four-letter strings $[F(1,23)=10.9$, $\mathrm{p}<.005]$. For "different" responses, the interaction between string type and orientation was significant $[\mathrm{F}(1,23)=5.0, \mathrm{p}<.05]$, and was mostly attributable to six-letter strings. When the data from four-letter strings were analyzed separately, this interaction did not approach significance $[\mathrm{F}(1,23)=1.73, \mathrm{p}>.20]$.

The overall error rate was approximately $2.1 \%$ for upright displays and $3.8 \%$ for rotated ones. There were more errors on trials for which the correct response was "different" $(4.0 \%)$ than there were for "same" trials (1.8\%). Errors followed a pattern similar to that found in Experiment I, the error rate being $11.5 \%$ for displays in which strings differed in only one position.

The small amount of serial-position data collected (from only those trials in which strings differed in one position) suggest that subjects tended to process upright letter strings from left to right and rotated strings from right to left. These data were, however, quite variable.

The finding that a reliable advantage in matching time for words could be obtained even for "different" responses confirms Eichelman's (1970) result. Our contention, that the effects of letter-sequence familiarity on "different" responses will be more strongly manifested when the "different" processor must deal with a substantial (and possibly familiar) portion of the display, would be supported by results showing that the advantage for words increased as the difference between string pairs became less salient. A highly significant interaction between string type and number of positions differing was found for six-letter strings $[F(2.46)=9.1, p<.001]$. This interaction was, however, only marginally significant for four-letter strings $[F(2,46)=2.7, p<.10]$. As might be expected from this line of reasoning, the largest word advantage for "different" responses $(115 \mathrm{msec})$ occurred for string pairs differing in only one position. This was especially true for upright pairs differing only in the last (rightmost) position $[242 \mathrm{msec}, t(23)$ $=18.1, \mathrm{p}<.001]$. 
Given the overall power in this experiment (all main effects were signiticant beyond the .005 level), the absence of any tendency towards an interaction between string type and orientation for four- and six-letter "same" responses $\left(F_{s}<1\right)$ and four-letter "different" responses $(p>.20)$ may say something about how processing is done in this task. Even though a significant interaction was found for six-letter "different" responses, the pattern of results seems sufficiently intriguing to warrant some speculation.

Consider the following model of what might happen in the present simultaneous matching task. The nodel (see Figure 2) is similar in some respects to Spoehr and Smith's (1973) model of word perception.

In the first (feature extraction) stage, features of letters in the display sufficient for their identification are extracted and passed on in the order in which they are extracted. No claim is made that this stage extracts all of the necessary features for one letter or pair of letters before moving on to the next, only that for fairly long displays, features from certain parts of the display will be extracted before features from other parts of the display. Direction of scanning would determine the order in which features would be extracted from different parts of the array. Manipulations of letter familiarity (e.g., type font, letter orientation) are assumed to influence primarily this stage of processing. The more features that are actually required for identification (presumably more are required for unfamiliar letters), the longer it takes to extract the necessary features.

The second (unitization) stage operates to provide units to higher levels of processing that are larger than those of simple features that it receives. These units may be larger than single letters, and in forming such units, processing in the unitization stage may be facilitated by orthographic or semantic information. The extent to which the orthographic legality of a display may facilitate its processing in the unitization stage will be influenced by the order in which its features are passed on by the feature extraction stage. For example, if the display BENT has its features received in the approximate order $B, E, N, T$, corresponding to a left-to-right order of feature extraction, facilitation will be greater than if they are received in the order $T, N, E, B$, corresponding to a right-to-left order of processing.
The advantage of words over nonwords is assumed to take place primarily at this second stage of processing. Either the units produced by this stage will be produced faster when processing is facilitated by orthographic information or else the units produced will be larger. This stage is also likely to be influenced by the subject's expectancies about whether or not words are likely to be encountered (cf. Aderman \& Smith, 1971: Schindler, Well, \& Pollatsek. 1974). As units are formed. they are made arailable to the third (comparison) stage, so that comparison of some units may begin before all feature extraction has been completed.

The comparison stage is self-terminating; when it cucounters a difference, it initiates a "different" response. If no difference has been encountered after comparison of all units, this stage will initiate a "same" response.

The predictions of this three-stage model are consistent with some of the major results of Experiment II, in that the model predicts (a) no interaction between string type and orientation (if subjects could be induced to process upright strings consistently from left to right and rotated strings from right to left). since the assumption is made that letter orientation and letter sequence familiarity influence separate stages of processing; (b) an effect of letter-sequence familiarity for both "same" and "different" responses, but a larger effect for "same" responses, since more units must be compared before initiating a "same" response; and (c) larger effects of letter-sequence familiarity for string pairs that differ in few positions than for pairs that differ in many positions, since, on the average, more units must be compared for string pairs that differ in few positions before a "different" response can be initiated.

The model, however, cannot readily explain the interaction between string type and orientation for six-letter "different" responses and, in addition, predicts two effects involving string length that were not found to be significant. The model predicts that, for "same" responses, the effects of rotation and the effects of letter sequence familiarity should be greater for six-letter strings than for four-letter strings. Neither the Length by Orientation nor the Length by String Type interaction was found to be significant for "same" responses or for "different" responses.

Perhaps the most important inconsistency is,

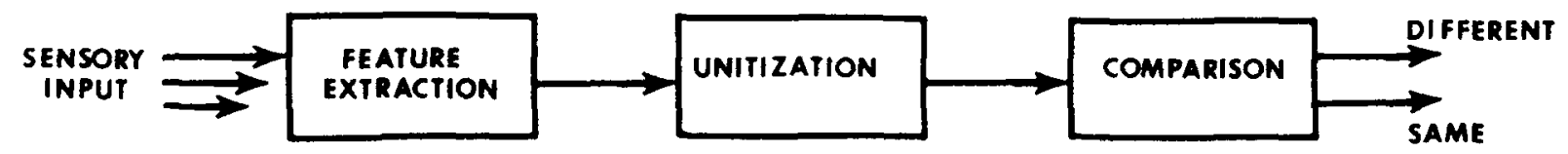

Figure 2. Three-stage model of the simultaneous matching task for letter strings. 
however, that "same" responses were much faster in Experiment II than would be predicted by the three-stage model. When "same" RTs were predicted from "different" RT data using a serial self-terminating model (in a manner analogous to that employed by Bamber, 1969), it was found that obtained "same" RTs were at least $400 \mathrm{msec}$ faster than predicted "same" RTs for four-letter conditions and at least $500 \mathrm{msec}$ faster for six-letter conditions.

One possibility is that "sames" might be faster than expected on the basis of the three-stage model simply because the subjects did not always compare all units before initiating a "same" response. Error rates were consistently higher for "different" trials (trials for which the correct response was "different") than for "same" trials, especially when string pairs differed in only one or two positions. Another possibility is that many of the "same" responses may have been initiated by a fast comparison process, such as that suggested by Bamber (1969) to account for the results of a successive string matching task. This fast comparison process (called the identity reporter) was hypothesized by Bamber to signal only if a pair was the "same"; otherwise, this process would not initiate a response.

Were such a process operative in Experiment II, it might be speculated that it could be a "crude" comparison process, sensitive to global aspects of the array and perhaps not sensitive to small differences (cf. Bamber's error rates when strings differed in only one position). "Same" responses in Experiment II would then be a mix of responses initiated by the fast crude comparison process and those initiated by the more careful comparison process of the three-stage model.

In any event, the high error rates obtained for strings which differed in few positions make the interpretation of some aspects of the data of both Experiments I and II rather difficult. It was thought, however, that some clarification of the situation might be achieved by a third experiment. If subjects are required to maintain a low error rate, even for string pairs that differ in few positions, they will, presumably, be less likely to initiate "same" responses prematurely. Also, if a two-process model is really required to explain the results of Experiment II, it might be possible to study the operation of one of these processes more adequately by generating a situation in which the other process was less likely to be active. In particular, if differences between strings were never very salient, and subjects were required to maintain low error rates, they might be less likely to employ a fast crude comparison process. ${ }^{2}$

\section{EXPERIMENT III}

Experiment III was essentially a replication of Experiment II, using sets of word and nonword pairs which could differ in, at most, one position. Experiment III also allowed another test of the predictions of the three-stage model in a situation in which the subjects would be less likely to initiate many premature "same" responses and would be less likely to employ any fast global comparison process.

Specifically for this new stimulus set, the model would predict (if low error rates could be maintained) (a) slower RTs for "different" responses than in Experiment II, because on the average, more of the display would have to be compared before a "different" response could be initiated; (b) slower RTs for "same" responses than in Experiment II, since, as differences would be less salient, fewer of the "same" responses would be initiated prematurely, or by a fast global comparison process (in fact, the model predicts that "same" responses should be as slow as the slowest "different" responses); (c) "different" $\mathrm{R} T s$ to increase monotonically with serial position of difference, as more units would have to be compared before initiating a "different" response; (d) effects of letter-sequence familiarity to increase monotonically with "different" RT, as the more units compared whose production has been facilitated by letter sequence familiarity, the greater the effect of this facilitation on RT; (e) effects of rotation to be larger for six-letter strings than for four-letter strings for both "same" and "different" responses; and (f) effects of letter-sequence familiarity to be greater for six-letter strings than for four-letter strings for both "same" and "different" responses.

\section{Method}

Subjects. Sixteen University of Massachusetts undergraduates served as subjects and received course credit for their participation. Each subject participated for two 1-h sessions on successive days.

Stimuli. Sets of four- and six-letter string pairs were constructed in which the half of the pairs that differed did so only in one position. For those string pairs that differed, the locations of the differences were equally likely to be in any of the serial positions. Nonword pairs were constructed by randomly permuting the order of letters in word pairs with the constraint that the permutation not spell a word.

Procedure. The procedure was similar to that employed in Experiment II with the following modifications: (a) blocks consisted of 48 trials each rather than 36 , and (b) data were collected from five blocks on each day, three containing six-letter strings and two containing four-letter strings. This disparity in the number of trial blocks containing four- and six-letter strings allowed the collection on each day of 12 "different" responses per subject for each serial position of the four- and six-letter strings. The order in which blocks containing strings of a given orientation and length were presented was counterbalanced in a fashion similar to that employed in Experiment II.

\section{Results and Discussion}

The mean RTs for "same" and "different" responses expressed as a function of length, orientation, and string type are presented in Table 3 . When an analysis of variance including both "same" and "different" RTs was performed, it was found that 
Table 3

Mean Response Times for Experiment III (in Milliseconds)

\begin{tabular}{|c|c|c|c|c|}
\hline \multirow{2}{*}{$\begin{array}{l}\text { Orien- } \\
\text { tation }\end{array}$} & \multicolumn{2}{|c|}{$\begin{array}{l}\text { Length and Type } \\
\text { Four-Letter Strings }\end{array}$} & \multicolumn{2}{|c|}{$\begin{array}{l}\text { of String Presented } \\
\text { Six-Letter Strings }\end{array}$} \\
\hline & Words & Nonwords & Words & Nonwords \\
\hline & \multicolumn{4}{|c|}{ "Same" Responses } \\
\hline \multirow[t]{2}{*}{$\begin{array}{l}\text { Upright } \\
\text { Rotated }\end{array}$} & $\begin{array}{r}917 \\
1339\end{array}$ & $\begin{array}{l}1115 \\
1628\end{array}$ & $\begin{array}{l}1256 \\
1984\end{array}$ & $\begin{array}{l}1802 \\
2304\end{array}$ \\
\hline & \multicolumn{4}{|c|}{ "Different" Responses } \\
\hline $\begin{array}{l}\text { Upright } \\
\text { Rotated }\end{array}$ & $\begin{array}{r}889 \\
1174\end{array}$ & $\begin{array}{l}1021 \\
1270\end{array}$ & $\begin{array}{l}1100 \\
1498\end{array}$ & $\begin{array}{l}1411 \\
1680\end{array}$ \\
\hline
\end{tabular}

there was a highly significant main effect of response type $[\mathrm{F}(1,15)=82.9 . \mathrm{p}<.001]$, and also that the effect of letter sequence familiarity was signiticantly greater for "same" than for "different" responses $[F(1,15)=58.1 . p<.001]$. Consequently. "same" and "different" RT data were analyzed separately using four-way analyses of variance: Length by Orientation by String Type by Subjects. For "same" responses. the effect of string type was highly signiticant $[F(1.15)=83.2, p<.001]$. As in Experiment II. there was no interaction between string type and orientation $[F(1.15)=1.36, p>.20]$, although words tended to enjoy a greater advantage over nonwords for upright $(372 \mathrm{msec})$ than for rotated $(303 \mathrm{msec})$ displays. The main effect of length was signiticant. as were all interactions involving length. Responses to six-letter strings were slower than those fo four-letter strings $[F(1,15)=249.7, p<.001]$ and were more aided by letter sequence familiarity $[F(1.15)=50.6, p<.001]$. While rotation slowed responses to both four- and six-letter strings $[\mathrm{F}(1,15)$ $=355.0, p<.001]$, responses to six-letter strings were slowed more $[\mathrm{F}(1,15)=28.8, \mathrm{p}<.001]$. Finally, the String Type by Length by Orientation interaction was signiticant $[F(1.15)=28.7 . p<.001]$. While, for six-letter strings. the effects of letter-sequence familiarity were greater for upright displays than for rotated displays, this was not the case for four-letter strings.

For "different" responses, those effects significant in the analysis of the "same" RT data were again all significant. In addition. there was a significant interaction between string type and orientation $[F(1.15)=5.2, p<.05]$. The advantage of words over nonwords was greater for upright $(222 \mathrm{msec})$ than for rotated ( $155 \mathrm{msec}$ ) displays.

The effect of string type was again signiticant $[F(1.15)=61.9 . p<.001]$. Responses to six-letter strings were slower than those to four-letter strings $[F(1.15)=248.6, p<.001]$ and were more aided by letter-sequence familiarity $[\mathrm{F}(1,15)=31.2, \mathrm{p}<$ $.001]$. Rotation slowed responses to all strings $[F(1.15)=494.2, p<.001]$, but slowed responses to six-letter strings more than to four-letter strings $[F(1.15)=4.9 . p<.05]$. Finally, with the same pattern of means as for the "same" responses, the String Type by Length by Orientation interaction was again signiticant $[\mathrm{F}(1,15)=5.3, \mathrm{p}<.05]$.

The overall error rate was $2.5 \%-2.2 \%$ for upright displays and $2.9 \%$ for rotated displays. There were more errors on trials for which the correct response was "different" $(4.0 \%)$ than there were on "same" trials $(1.1 \%)$.

Since the string pairs used in Experiment III were constructed so as to differ in, at most, one position, it was possible to examine the serial position data more closely than had been the case for Experiment II. When serial position curves ("different" $\overline{\mathrm{RT}}$ vs. serial position of difference) were plotted for each subject, it was found that for upright strings $\mathrm{RT}$ increased with position of difference for 15 of 16 subjects. indicating that subjects tended to process upright strings from left to right. For rotated strings, the data from 13 of the 16 subjects indicated that rotated strings were processed from right to left. Three subjects produced data which suggested that they were processing rotated six-letter strings (but not four-letter strings) from left to right. The data from these four discrepant subjects have been excluded from all subsequent analyses. ${ }^{3}$

The averaged serial-position curves for the remaining 12 subjects are displayed in Figure 3. As can be seen from Figure $3 . \overline{R T}$ increased monotonically for the first three positions of four-letter strings and the first five positions of six-letter strings.

The tendency for $\overline{\mathrm{RT}}$ to drop in the last serial position for some conditions may reflect the greater discriminability of the end letters in a display as opposed to the enclosed letters. It should be emphasized that these data do not necessarily imply that subjects employed a strictly serial scan in searching for differences (i.e., processed one serial position fully before beginning the next). The data imply only that the processing of early serial positions tended to be completed before that of later positions. The serial-position data effectively rule out any possibility that word pairs were primarily matched by fully processing both words and comparing their meanings. Were this the case, there would be no reason to expect ascending serial-position curves. In fact. the data do not support any model which assumes both that the encoding of the strings is completed before any comparison takes place and that the advantage of words over nonwords primiarly intluences encoding time. Such a model would predict that intercepts (reflecting encoding time) would be higher for non words than for words. No effect of letter sequence familiarity on intercepts was obtained $[F(1,11)=1.3, p>.20] .^{4}$

While the serial position data were subjected to many analyses, two were most important: curves for nonwords had greater slopes than did curves for words 


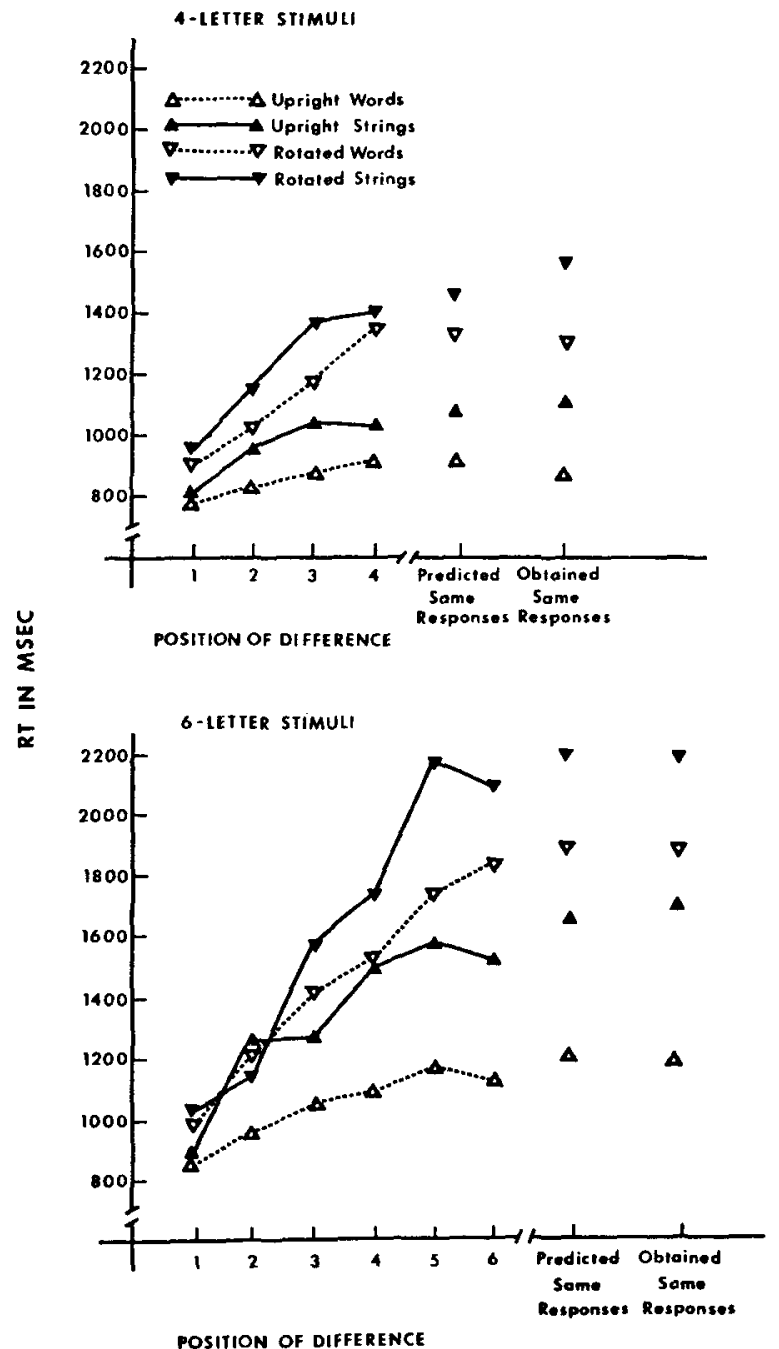

Figure 3. Serial position curves for Experiment III ( $=12$; the data of four subjects were excluded).
$[F(1,11)=26.4, p<.001]$, and curves for rotated displays had greater slopes than those for upright displays $[F(1,11)=29.0, p<.001]$. Processing apparently proceeded throughout the strings more slowly for nonwords than for words and more slowly for rotated strings than for upright strings.

As can be seen from Figure 3, "same" responses in this experiment seemed to be initiated primarily upon completion of an unsuccessful search for differences. It was possible to generate from the serial position data the best linear predictions for "same" RTs given this assumption. ${ }^{5}$ Of course, any direct comparison of the magnitudes of predicted and obtained RTs in this experiment is subject to the criticism that the subjects made "same" responses with their left hands and "different" responses with their right hands. Any "bias" so incurred would, however, be expected to affect only the absolute magnitudes of predicted RTs and not their relative sizes in the various stimulus conditions employed. In any event, the correlation between predicted and same RTs was .993 . Apparently, the fast global comparison process does not initiate many "same" responses when differences between stimuli are not salient and fairly high accuracy is required.

The results confirm the hypothesis that the effects of letter-sequence familiarity on processes responsible for "different" responses may be observed, given that a substantial portion of the display is processed before a response is initiated. The data, in fact, also tend to contirm the prediction of the three-stage model that the effects of letter-sequence familiarity should increase monotonically with "different" RT. While the relevant data are contained within Figure 3, this point is best demonstrated by Figure 4, which is a plot of letter-sequence familiarity effects against mean time required to make a response to upright word pairs. A similar relationship with a lower slope is

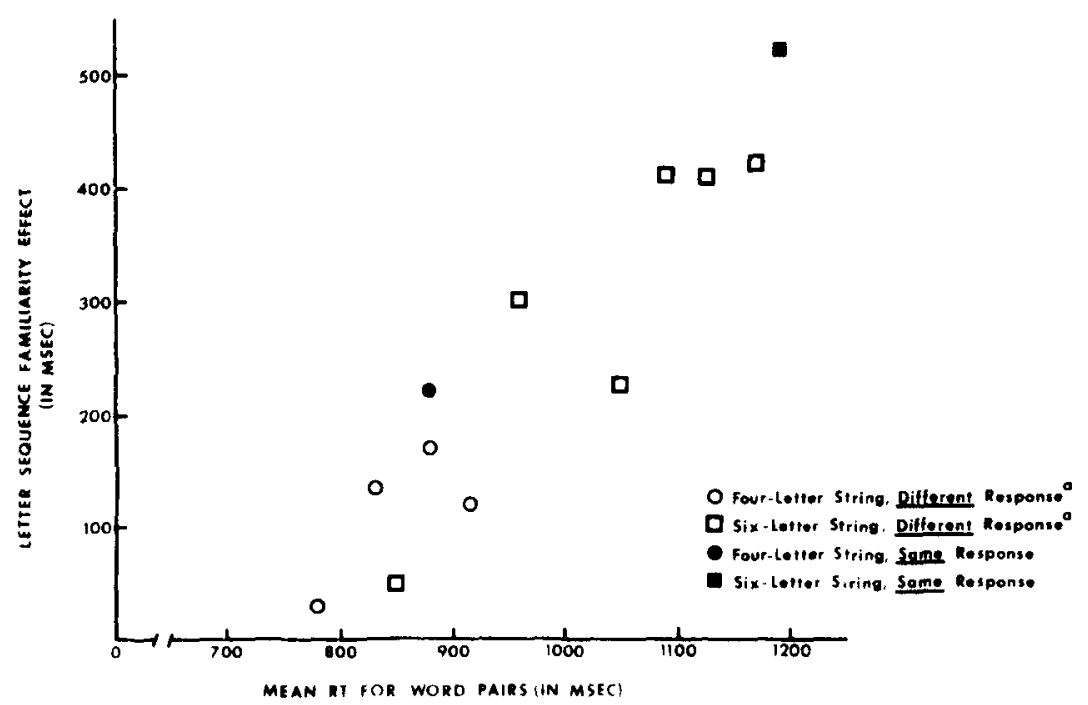

Figure 4. Letter-sequence familiarity effect vs. mean RT for upright words in Experiment III. ane point for each serial position. 
obtained for rotated strings. As the amount of processing tine required to make a response increases (roughly as a linear function of serial position) and more of the display is processed, the magnitude of the advantage of words over nonwords increases. Figure 4 suggests that when a "different" response can be initiated after a minimum of processing. little or no effect of letter-sequence familiarity should be observed.

The three-stage model is consistent with almost all aspects of the data from Experiment III, all six of the predictions mentioned in the introduction to this experiment being supported. The major problem in the data for the model is the String Type by Orientation interaction for "different" responses. When four- and six-letter data were analyzed separately, it was found that while there was no suggestion of this interaction for either four-letter "same" or four-letter "different" responses (Fs $<1$ ), the interaction was significant for six-letter "same" $[F(1.11)=7.26 . p<.025]$ and six-letter "different" responses $[F(1.11)=10.92, p<.01]$. Perhaps this result may be due to the fact that the difficulty of scanning rotated strings from right to left is greater for six-letter strings than for four-letter strings. There is some weak evidence in support of this-those subjects.whose data were deleted from much of this analysis because their serial position data strongly suggested they were processing rotated six-letter strings from left to right still tended to process rotated four-letter strings from right to left.

Finally, it should be noted that the times required to match word strings (particularly in Experiment III) are long relative to the times required to process the meaning of a word. when that is what the task requires (e.g.. Meyer \& Schvaneveldt, 1971). Even though matching of complex letter strings can be aided by letter-sequence familiarity (and, hence. by orthographic and perhaps semantic information), any attempts to generalize the results of simultaneous matching tasks to processes such as reading for meaning must be done with considerable caution, and may, at best. be premature.

\section{REFERENCES}

Aderman. D.. \& Smith, E. E. Expectancy as a determinant of functional units in perceptual recognition. Cognitive Psychology. 1971. 2. 117.129.

BAMBER. D. Reaction times and error rates for "same-different" judgments of multidimensional stimuli. Perception \& Psychophysics, $1969,6,169.174$.

Barron, R, W., \& Pittenger, J. B. The effect of orthographic structure and lexical meaning on same-different judgments.
Quarterly Journal of Experimental Psychology, 1974. 26. $566-581$.

Cattell, J. M. The time taken up by cerebral operations. Mind, 1886, 11, 277.292. 524-538.

Egeth. H., \& Blecker, D. Differential etfects of tamiliarity on judgments of sameness and difference. Perception \& Psychophysics, 1971. 9. 321-326.

Erchelman, W. H. Familiarity effects in a simuitaneous matching task. Journal of Experimental Psychology. 1970, 86. 275-282.

HENDERSON, L. A word superiority effect without orthographic assistance. Quarterly Journal of Experimental Psychology. 1974. 26. 301-311.

Hochberc, J. In the mind's eye. In R. Haber (Ed.), Contemporary theory and research in visual perception. New York: Holt, 1968.

Krueger. L. E. Search time in a redundant visual display. Journal of Experimental Psychology, 1970, 83. 391-399.

Meyer. D. E., \& Schvaneveldt, R. W. Facilitation in recognizing pairs of words: Evidence of a dependence between retrieval operations. Joumal of Experimental Psychology. 1971. 90. 227-234.

Reicher, G. M. Perceptual recognition as a function of meaningfulness of stimulus material. Journal of Experimental Psychology, 1969, 81, 275-280.

Schindler, R. M.. Well, A. D., \& Pollatsek, A. Effects of segmentation and expectancy on matching time for words and nonwords. Journal of Experimental Psychology, 1974, 103, 107-111.

SILVERMAN, W. P. The perception of identity in simultaneously presented complex visual displays. Memony \& Cognition, 1973. 1. 459.466 .

SPOEhr. K. T. \& \& SMith, E. E. The role of syllables in perceptual processing. Cognitive Psychology, 1973, 5, 71-89.

\section{NOTES}

1. Reading from Eichelman's (1970) Figure 1. FEs for four- and six-letter "same" responses were approximately 150 and $200 \mathrm{msec}$, respectively.

2. In a recent paper, Silverman (1973) reported two digit string matching experiments relevant to the issue of whether a twoprocess model [one process of which is Bamber's (1969) identity reporterl is really necessary to explain the results of matching experiments. Silverman reported evidence implying that the identity reporter, if it really exists, has a limited capacity in terms of stimulus discriminability.

3. When the ANOVAs reported earlier were redone using data from only the remaining 12 subjects, the patterns of significance were essentially identical to those that had been obtained from the data of all 16 subjects.

4. This argument depends on the serial position curves for the various conditions being relatively linear. The best linear fits to the data in the first three serial positions of four-letter string conditions each accounted for at least $98 \%$ of the variability. The best linear fits to the data in the first five serial positions of six-letter string conditions each accounted for at least $91 \%$ of the variability.

5. For example, in a six-letter condition, predicted $\mathrm{RT}_{\text {same }}$ $=$ intercept $+6 \times$ slope.

(Received for publication December 26, 1974; accepted March S, 1975.) 